\title{
AN IN VITRO MODEL OF ISCHEMIA: METABOLIC AND ELECTRICAL ALTERATIONS IN THE HIPPOCAMPAL SLICE ${ }^{1}$
}

\author{
TIM S. WHITTINGHAM, ${ }^{2}$ W. DAVID LUST, AND JANET V. PASSONNEAU \\ Laboratory of Neurochemistry, National Institute of Neurological and Communicative Disorders and Stroke, National Institutes \\ of Health, Bethesda, Maryland 20205
}

Received August 5, 1983; Revised November 4, 1983; Accepted November 4, 1983

\begin{abstract}
The transverse guinea pig hippocampal slice preparation was used to model the metabolic changes which occur in vivo during ischemia and recovery. Perfusing brain slices with medium devoid of glucose and oxygen elicits rapid decreases in phosphocreatine, ATP, intracellular $\mathrm{pH}$, and in the evoked field potential recorded in the dentate gyrus. AMP and creatine rise during this period, while $\mathrm{ADP}$ and lactate levels remain unchanged. Cyclic AMP exhibits a transient increase in concentration. With the exception of ADP and lactate, these responses are very similar to those observed during in vivo ischemia. The return of glucose and oxygen to the incubation medium reverses these metabolic and electrophysiological effects and also leads to pronounced elevations in cyclic nucleotide concentrations. Metabolite concentrations approach, but do not reach, in vitro steady state levels during the first $30 \mathrm{~min}$ of recovery. Total adenylate and creatine steady state levels are approximately $50 \%$ of in vivo concentrations. The results suggest that, although hippocampal slices differ metabolically from in vivo tissue, they exhibit a similar pattern of metabolic responses to ischemic and reflow conditions.
\end{abstract}

The metabolic changes which occur during ischemia in vivo have been detailed previously (Lowry et al., 1964; Ljunggren et al., 1974; Kobayashi et al., 1977). Metabolic changes generally appear within $30 \mathrm{sec}$ of decapitation or carotid clamp ischemia; a rapid fall in phosphocreatine (PCr) and glucose levels is followed by a more gradual decline in ATP and glycogen concentrations (Lowry et al., 1964). The high rate of glucose and oxygen utilization in brain and the rapid onset of electrical failure (Hirsch et al., 1957; Urbanics et al., 1979) in all conditions which affect glucose or oxygen utilization suggest that there is a relationship between energy production (i.e., ATP) and maintenance of synaptic transmission. However, the time required for fixation of brain in situ has hindered accurate temporal correlations between electrophysiological deficits and metabolic changes during ischemia.

Recently, using the hippocampal slice preparation, a relationship has been shown between ATP levels and the continuation of evoked responses during anoxia (Whittingham and Lipton, 1981; Lipton and Whittingham,

\footnotetext{
${ }^{1}$ We wish to express our appreciation for the technical assistance of Ms. Gretchen Feussner and Mr. Dimitri Christakis, and the clerical assistance of Ms. Lois V. Trigg.

" To whom correspondence should be sent, at his present address: Division of Neurological Surgery, University Hospitals, Case Western Reserve University, 2074 Abington Road, Cleveland, $\mathrm{OH} 44106$.
}

1982). However, a comparison of anoxic (Kaasik et al., 1970) and ischemic (Ljunggren et al., 1974) changes suggests that ischemia produces more rapid and severe metabolic perturbations than does anoxia. Additionally, ischemia may lead to a "no-reflow phenomenon" (Ames et al., 1968) in some brain regions which could compromise recovery in those areas. If the hippocampal slice preparation can be used to model the metabolic events which occur during ischemia, specific metabolic effects on electrophysiological function during ischemic and subsequent reflow periods might be determined. In addition, the ability to manipulate the environment rapidly, to add agents to discrete regions selectively, and the absence of a blood-brain barrier combine to facilitate assessment of numerous ischemic parameters and of anti-ischemic treatments. Finally, given the flexibility of in vitro systems, it may eventually be possible to differentiate between the effects of oxygen and glucose deprivation and the effects due to cessation of flow.

The goals of this study were 2-fold: (1) to observe the metabolic changes which occur in hippocampal slices deprived of both glucose and oxygen but in the presence of continued flow, and to compare them to those changes that occur in brain following decapitation; (2) to determine if there are correlations between recovery of metabolite levels during an in vitro "reflow" period and the return of evoked potentials. Of particular interest are the levels of high energy phosphates $(\sim \mathrm{P}=\mathrm{PCr}$ and ATP $)$, 
intracellular $\mathrm{pH}\left(\mathrm{pH}_{\mathrm{i}}\right)$, and the cyclic nucleotides (cAMP and cGMP), since a perturbation in these conditions may affect synaptic transmission.

\section{Materials and Methods}

Male guinea pigs weighing 350 to 450 gm were decapitated, and their brains were rapidly removed into KrebsRinger bicarbonate buffer (referred to as artificial cerebral spinal fluid, ACSF) devoid of glucose and equilibrated with $95 \% \mathrm{~N}_{2} / 5 \% \mathrm{CO}_{2}$ at $37^{\circ} \mathrm{C}$. Standard ACSF contained $125 \mathrm{mM} \mathrm{NaCl}, 3.0 \mathrm{mM} \mathrm{KCl}, 1.4 \mathrm{mM} \mathrm{KH}_{2} \mathrm{PO}_{4}$, $1.3 \mathrm{mM} \mathrm{MgSO}_{4}, 26.0 \mathrm{mM} \mathrm{NaHCO}, 2.4 \mathrm{mM} \mathrm{CaCl}_{2}$, and $4.0 \mathrm{~mm}$ glucose and was equilibrated with $95 \% \mathrm{O}_{2} / 5 \%$ $\mathrm{CO}_{2}$ (pH 7.4 to 7.5). The hippocampi were removed and 400- to 500- $\mu \mathrm{m}$ slices were prepared as described previously (Lipton and Whittingham, 1979). Three experimental paradigms were used. (1) The excised hippocampi and subsequent slices were maintained for $7 \mathrm{~min}$ in $1 \mathrm{ml}$ of ACSF devoid of glucose and oxygen before perfusion in the recording chamber for $33 \mathrm{~min}$ of recovery in standard ACSF. (2) Tissue was treated as in condition 1 , but the initial ischemic period was extended to $15 \mathrm{~min}$. (3) Slices were treated as in condition 1 and after the recovery period were exposed to a secondary ischemic period of $7 \mathrm{~min}$ by perfusion with ACSF devoid of glucose and oxygen. A secondary recovery period of $33 \mathrm{~min}$ followed. The three experimental paradigms are shown in Table I. Condition 3 is the in vitro model of ischemia and will be referred to as the "secondary" ischemia. Conditions 1 and 2 were used to represent the metabolic changes which occur following decapitation. The brain remained intact for only a portion (2 to $4 \mathrm{~min}$ ) of the initial ischemic periods because hippocampal slices had to be prepared from the tissue during this time. During the remainder of the initial ischemia the slices were placed in $1 \mathrm{ml}$ of ACSF in order to approximate in vivo conditions more closely. The term "in vivo" will be used to refer to previous studies in which the ischemic and reflow periods were examined in surgically prepared intact animals. A flow rate of $25 \mathrm{ml} / \mathrm{min}$ was maintained in the recording chamber during recovery periods and during the secondary ischemia. The term "reflow," then, refers only to the return of glucose and oxygen to the ACSF and is used for the period correlating with the return of blood flow in in vivo studies.

\section{TABLE I}

Experimental protocol for the evaluation of postdecapitation and in vitro ischemia in guinea pig hippocampus

Guinea pigs were decapitated and hippocampal slices were prepared as described under "Materials and Methods." In vitro ischemia refers to perfusion in the absence of glucose and oxygen. In vitro recovery refers to perfusion by ACSF containing glucose and oxygen.

\begin{tabular}{ccccc}
\hline Paradigm & $\begin{array}{c}\text { Post- } \\
\text { decapitation } \\
\text { Ischemia }\end{array}$ & $\begin{array}{c}\text { In Vitro } \\
\text { Recovery }\end{array}$ & $\begin{array}{c}\text { In Vitro } \\
\text { Secondary } \\
\text { Ischemia }\end{array}$ & $\begin{array}{c}\text { In Vitro } \\
\text { Secondary } \\
\text { Recovery }\end{array}$ \\
\hline & $\min$ & $\min$ & $\min$ & $\min$ \\
1 & 7 & 33 & & \\
2 & 15 & 35 & & \\
3 & 7 & 33 & 7 & 33
\end{tabular}

Decapitation $\quad \frac{\text { flow rate }=25 \mathrm{ml} / \mathrm{min}}{\text { stimulate and record }}$
The perforant path axons of some slices were stimulated at 4 pulses/min with bipolar tungsten electrodes, and the evoked potentials were recorded in the dentate gyrus using 2 - to 3 -megohm tungsten electrodes. The evoked responses were amplified $\times 10$ and displayed on a storage oscilloscope.

Individual slices were removed during the ischemic and subsequent recovery periods and frozen in liquid nitrogen. Slices were stored at $-60^{\circ} \mathrm{C}$. Tissue samples were homogenized in $0.3 \mathrm{~N}$ perchloric acid and centrifuged at $10,000 \times g$ for $5 \mathrm{~min}$. The supernatant was neutralized with $3 \mathrm{~N} \mathrm{KHCO}_{3}$ and stored at $-60^{\circ} \mathrm{C}$. The protein pellet was resuspended in $0.1 \mathrm{~N} \mathrm{NaOH}$, and protein content was determined as described by Lowry et al. (1951). PCr, ATP, ADP, and AMP were assayed using the luciferin-luciferase technique (Lust et al., 1981). Creatine $(\mathrm{Cr})$ and lactate were assayed fluorometrically (Lowry and Passonneau, 1972) and the cyclic nucleotides by radioimmunoassay (Steiner et al., 1972). The sensitivity of the cyclic GMP assay was enhanced by acetylation of the cGMP (Harper and Brooker, 1975).

Adenylate energy charge (E.C.) was calculated as described by Atkinson (1968):

$$
\text { E.C. }=\frac{(\mathrm{ATP})+0.5(\mathrm{ADP})}{(\mathrm{ATP})+(\mathrm{ADP})+(\mathrm{AMP})}
$$

Intracellular $\mathrm{pH}$ was estimated from the creatine kinase equilibrium (Rose, 1968), where:

$$
\left(\mathrm{H}^{+}\right)=\frac{(\mathrm{ATP})(\mathrm{Cr})}{(\mathrm{ADP})(\mathrm{PCr})} \times \frac{1}{K^{\prime}}
$$

The value used for the apparent equilibrium constant $\left(K^{\prime}\right)$ was $1.41 \times 10^{8}$, as estimated from the data of MacMillan and Siesjo (1972). Using this $K^{\prime}$ value in our system appears to be legitimate as similar values for $\mathrm{pH}_{\mathrm{i}}$ were obtained in normoxic slices (T. S. Whittingham and $\mathrm{P}$. Lipton, unpublished data) using a different method to estimate $\mathrm{pH}_{\mathrm{i}}$, the 5,5-dimethyl-2,4-oxazolidinedione (DMO) weak acid technique (Waddell and Butler, 1959).

The enzymes used for metabolite analyses were obtained from Boehringer-Mannheim. Compounds used for radioimmunoassay were supplied by Becton-Dickinson. All other chemicals were obtained from Sigma. Statistical comparisons were made using the Student's two-tailed $t$ test. Any differences discussed in the text were significant at $p<0.01$ or greater.

\section{Results}

Electrophysiology. The recovery rate of the evoked response was the same following both decapitation and secondary (in vitro) 7-min ischemic episodes (Table II). Extending the initial decapitation ischemia from 7 to 15 min delayed the return of the evoked postsynaptic field potential (PSP) by approximately $2 \mathrm{~min}$ and decreased the magnitude of the maximal steady state response by $80 \%$. The duration of the postdecapitation ischemia ( 7 or $15 \mathrm{~min}$ ) did not significantly affect the electrophysiological sensitivity of the tissue to a subsequent in vitro ischemia. The evoked response in tissue which was previously ischemic for $15 \mathrm{~min}$ began to decrease at 0.75 


\section{TABLE II}

Evoked response during ischemia and recovery from ischemia

In "A," the orthodromic evoked potential in the dentate granule cell layer was monitored during recovery from 7 or $15 \mathrm{~min}$ of postdecapitation ischemia or $7 \mathrm{~min}$ of in vitro ischemia. The perforant path was stimulated every $15 \mathrm{sec}$. The values in the "PSP" and "AP" columns are the times at which the postsynaptic field potential and the action potential portion of the evoked response first became apparent following the onset of reflow. The maximal response is the largest magnitude AP wave that could be obtained following a 1-hr in vitro recovery period. All values are the mean \pm SEM of six determinations. In " $B$," the duration of the initial (postdecapitation) ischemic episode was tested for its effect on the maintenance of the evoked potential during a subsequent in vitro ischemic period. Slices were allowed to recover for 33 or 35 min prior to the secondary ischemia. "First decrease" is the time at which the AP portion of the evoked response first exhibits a marked $(20 \%)$ decrease in magnitude. "Abolished" refers to the time at which the evoked response is isoelectic. All values are the mean \pm SEM of six determinations.

\begin{tabular}{|c|c|c|c|}
\hline \multicolumn{4}{|c|}{ A. Onset of evoked response following ischemia } \\
\hline $\begin{array}{l}\text { Duration of } \\
\text { Ischemia }\end{array}$ & PSP & $\mathrm{AP}$ & $\begin{array}{l}\text { Maximal } \\
\text { Response }\end{array}$ \\
\hline $\min$ & \multicolumn{2}{|c|}{$\min$} & $m V$ \\
\hline 7 & $5.25 \pm 0.75$ & $9.50 \pm 0.50$ & $1.4 \pm 0.3$ \\
\hline 7 (secondary) & $5.50 \pm 1.50$ & $8.50 \pm 2.75$ & \\
\hline 15 & $7.75 \pm 1.00^{\circ}$ & $11.00 \pm 1.50$ & $0.3 \pm 0.1^{a}$ \\
\hline
\end{tabular}

B. Disappearance of evoked response during in vitro ischemia

\begin{tabular}{|c|c|c|}
\hline $\begin{array}{l}\text { Duration of } \\
\text { Initial Ischemia } \\
\text { (In Vivo })\end{array}$ & \multicolumn{2}{|c|}{ (in Vitro) } \\
\hline $\min$ & \multicolumn{2}{|c|}{$\min$} \\
\hline 7 & $1.00 \pm 0.10$ & $1.75 \pm 0.10$ \\
\hline 15 & $0.75 \pm 0.10$ & $1.50 \pm 0.10$ \\
\hline
\end{tabular}

${ }^{a} p<0.01$ compared to postischemia value.

$\mathrm{min}$, whereas that of tissue previously ischemic for $7 \mathrm{~min}$ began to decrease at $1 \mathrm{~min}$ of the secondary ischemia (Table IIB), although the difference was not significant. The rate of response decrement was more rapid than observed under similar conditions during anoxia in the presence of $4 \mathrm{mM}$ glucose, in which the response exhibited an initial decrement at $2.25 \mathrm{~min}$ and was abolished in 4.25 min (Lipton and Whittingham, 1982).

Metabolites. ATP levels were minimal within $7 \mathrm{~min}$ of ischemia, at levels 5 to $10 \%$ of control. Extending the ischemic period to $15 \mathrm{~min}$ produced little additional change but did delay the recovery of ATP levels during the reflow period (Fig. $1 A$ ). The tissue exhibited a more rapid fall in ATP during the secondary ischemia, whereas the rate of recovery during reflow was identical whether the ischemia was a single 7-min period following decapitation or was the secondary in vitro 7-min period.

Concomitant with the rapid fall in ATP during the postdecapitation ischemia there was a 9-fold rise in ADP concentration, peaking at $3 \mathrm{~min}$ (Fig. $1 B$ ). No rise was observed during the secondary in vitro ischemia, which may be attributed to the decrease in total adenylates (see "Discussion"). AMP concentration increased in both the postdecapitation and in vitro ischemic slices, peaking at 7 min (Fig. 1C). Reflow caused a rapid fall in the AMP content of all three groups, which cannot be totally accounted for by increases in ATP and ADP during that time.
Tissue total adenylate content decreased by $50 \%$ or more within $15 \mathrm{~min}$ following decapitation and was independent of the onset of perfusion. No further decrement was observed during the secondary ischemic period.

Energy charge fell to minimal levels within $7 \mathrm{~min}$ of ischemia for both postdecapitation and in vitro tissue (Fig. 1D). The rate of energy charge recovery was the same for both postdecapitation ischemic groups ( 7 and $15 \mathrm{~min}$ ) even though ATP recovery was delayed in the 15-min ischemic group. The in vitro model exhibited a slightly more rapid return toward steady-state levels. Steady-state energy charges following recovery from postdecapitation and in vitro ischemia were similar despite the decrease in total adenylate content in vitro.

Phosphocreatine fell more rapidly and to a greater degree than ATP during postdecapitation and secondary ischemic periods (Fig. $2 A$ ), with levels being minimal within 2 to $5 \mathrm{~min}$. Fifteen-minute ischemic episodes delayed the recovery of $\mathrm{PCr}$ levels to the same extent that they delayed ATP recovery. The rates of recovery from postdecapitation and secondary ischemic periods of 7 min duration were identical. After $33 \mathrm{~min}$ recovery the $\mathrm{PCr} / \mathrm{ATP}$ ratio was $2.34 \pm 0.08$, which is elevated compared to the in vivo control value $(1.92 \pm 0.05)$.

Creatine levels increased initially during the postdecapitation ischemia as $\mathrm{PCr}$ fell (Fig. $2 B$ ), but there was a net decrease in total creatine $(\mathrm{PCr}+\mathrm{Cr}$ ) from control values of $115.7 \pm 4.4 \mathrm{nmol} / \mathrm{mg}$ of protein to $81.4 \pm 2.8$ after 7 min and $74.4 \pm 2.4$ after 15 min of ischemia. Total creatine levels fell slowly during the initial $30 \mathrm{~min}$ of recovery following $7 \mathrm{~min}$ of postdecapitation ischemia, stabilizing at $70.4 \pm 2.4 \mathrm{nmol} / \mathrm{mg}$ of protein, 50 to $60 \%$ of in vivo controls. There was a greater fall in the 15min ischemic group, to $60.2 \pm 2.0 \mathrm{nmol} / \mathrm{mg}$ of protein.

The calculated $\mathrm{pH}_{\mathrm{i}}$, using the creatine kinase equilibrium, fell 0.4 and $0.6 \mathrm{pH}$ unit within 5 min of postdecapitation and secondary ischemia, respectively (Fig. $3 A$ ), with an additional 0.1 unit fall when the initial ischemic episode was extended to $15 \mathrm{~min}$. Upon reflow, $\mathrm{pH}_{\mathrm{i}}$ returned to relatively stable levels within $15 \mathrm{~min}$ and was substantially recovered in the first $3 \mathrm{~min}$. Recovery from 15-min ischemia occurred at a rate similar to that of the 7-min groups, although steady state levels were reached more slowly because of the more acidic starting point. In vitro steady state levels appear to be more alkaline than those in vivo.

Lactate levels rose 14-fold in the first $5 \mathrm{~min}$ and decreased between 7 and $15 \mathrm{~min}$ of postdecapitation ischemia (Fig. $3 B$ ). There was a linear decrease of lactate in both 7- and 15-min groups during the subsequent perfusion with glucose and oxygen present. Intracellular $\mathrm{pH}$ fell during in vitro ischemia despite the fact that there was no accumulation of lactate.

The changes in cAMP concentrations during ischemia and reflow were biphasic in the postdecapitation group (Fig. $4 A$ ). After 5 min of ischemia, there was an increase from control values of 6.64 to $200 \mathrm{pmol} / \mathrm{mg}$ of protein. After 15 to $20 \mathrm{~min}$ of incubation in the presence of oxygen and glucose, there was a further increase to over $600 \mathrm{pmol} / \mathrm{mg}$ of protein. The rate and degree of recovery of cAMP concentrations were slower than for the other measured metabolites. The concentration of cAMP after 

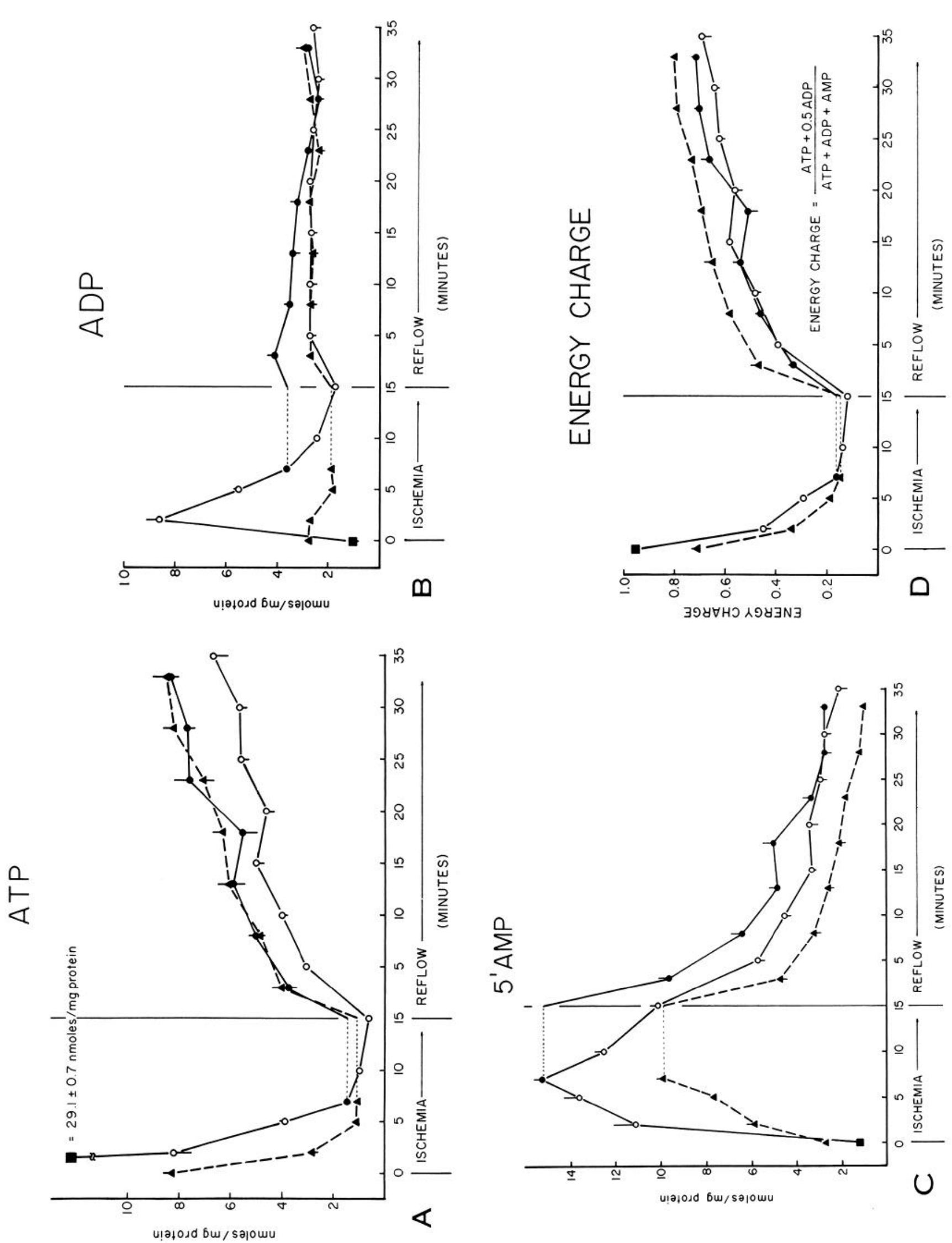

สี ธี

要

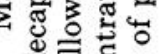

实记

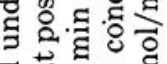

현

ॠ

घี $\tilde{x}^{\circ}$

㐘 +1

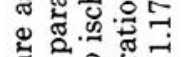

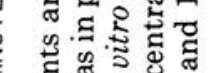

ฐ $\cong$.

ब हैं०

政宁 +1

ॠ

额

ठิ์

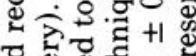

สี ญ्ष्ठ

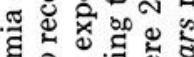

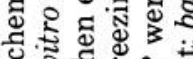

.

ㅇㅣㅀㅀ

ปี่

ษึ छี

क ส

ㅍ.

㻤 हี

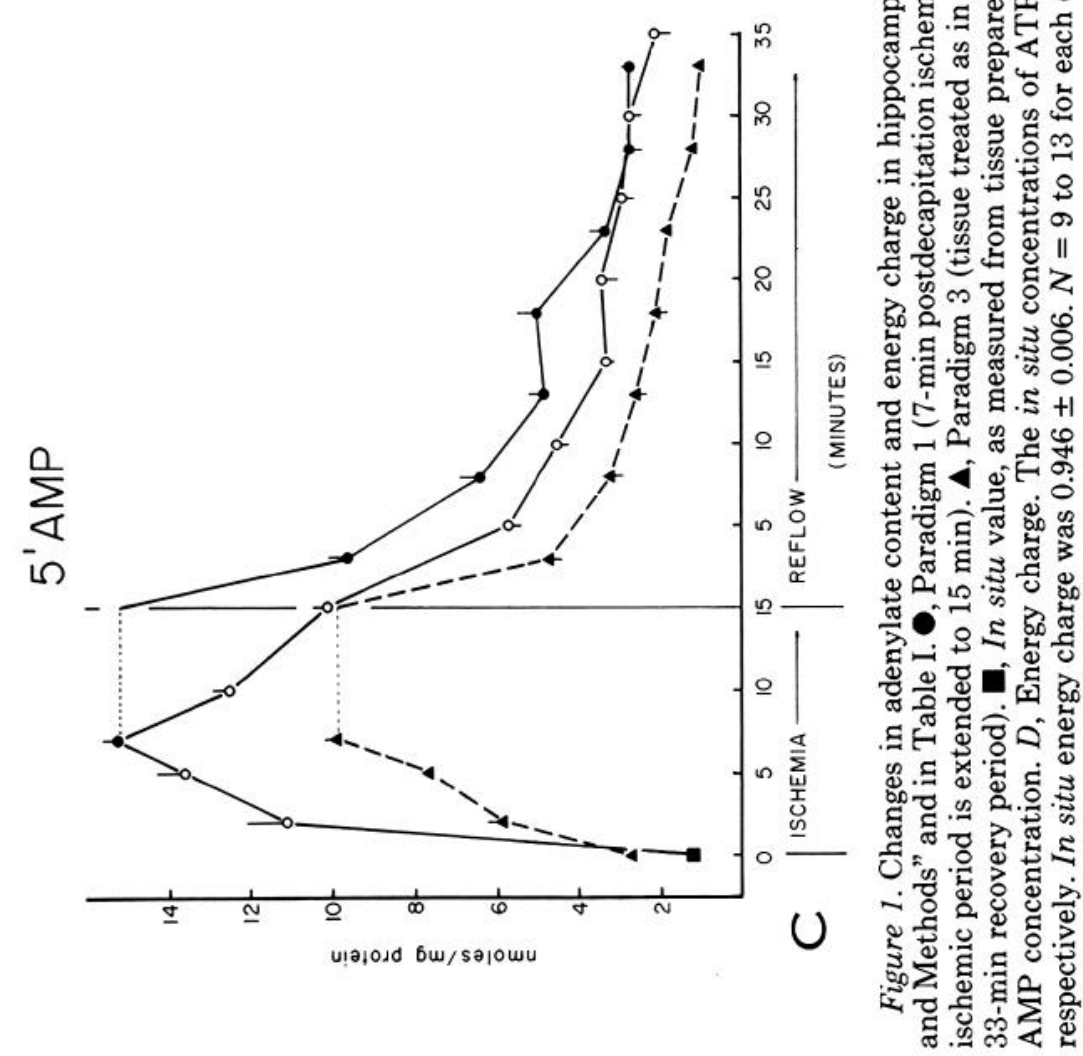



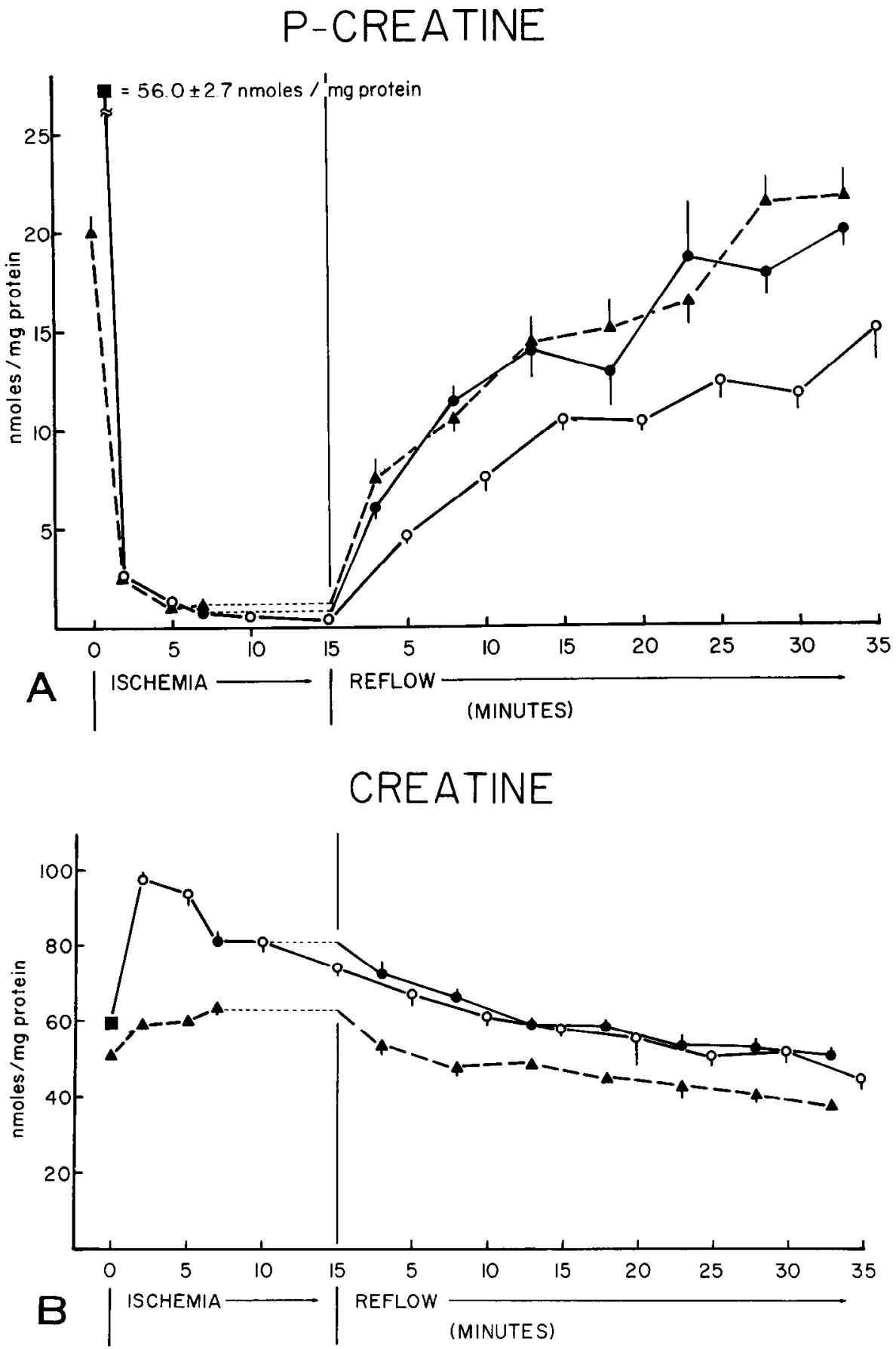

Figure 2. Changes in $\mathrm{PCr}$ and creatine content in hippocampal slices during ischemia and recovery. Groups are described in the legend to Figure 1 . The in situ concentrations of $\mathrm{PCr}$ and $\mathrm{Cr}$ were $56.0 \pm 2.7$ and $59.7 \pm 2.2 \mathrm{nmol} / \mathrm{mg}$ of protein, respectively. $A$, Phosphocreatine concentration. $B$, Creatine concentration. $N=9$ to 13 for each experimental point; bars represent SEM.

$7 \mathrm{~min}$ of ischemia and $33 \mathrm{~min}$ of recovery was still 70 fold greater than control values. During the secondary ischemic period, the cAMP levels fell, but there was a subsequent increase during the next recovery period similar to that in the first series.

There was no significant change in cGMP during ischemia in the postdecapitation slices (Fig. $4 B$ ). The increases in cGMP content in the reflow period appeared to be dependent on the duration of the initial ischemia period, as a greater increase was seen in the 15-min than in the 7-min ischemic group. During secondary ischemia, cGMP levels decreased somewhat and increased 2-fold during the subsequent reflow. As was seen with cAMP, cGMP levels returned toward basal levels more slowly than did those compounds more directly associated with energy metabolism. 

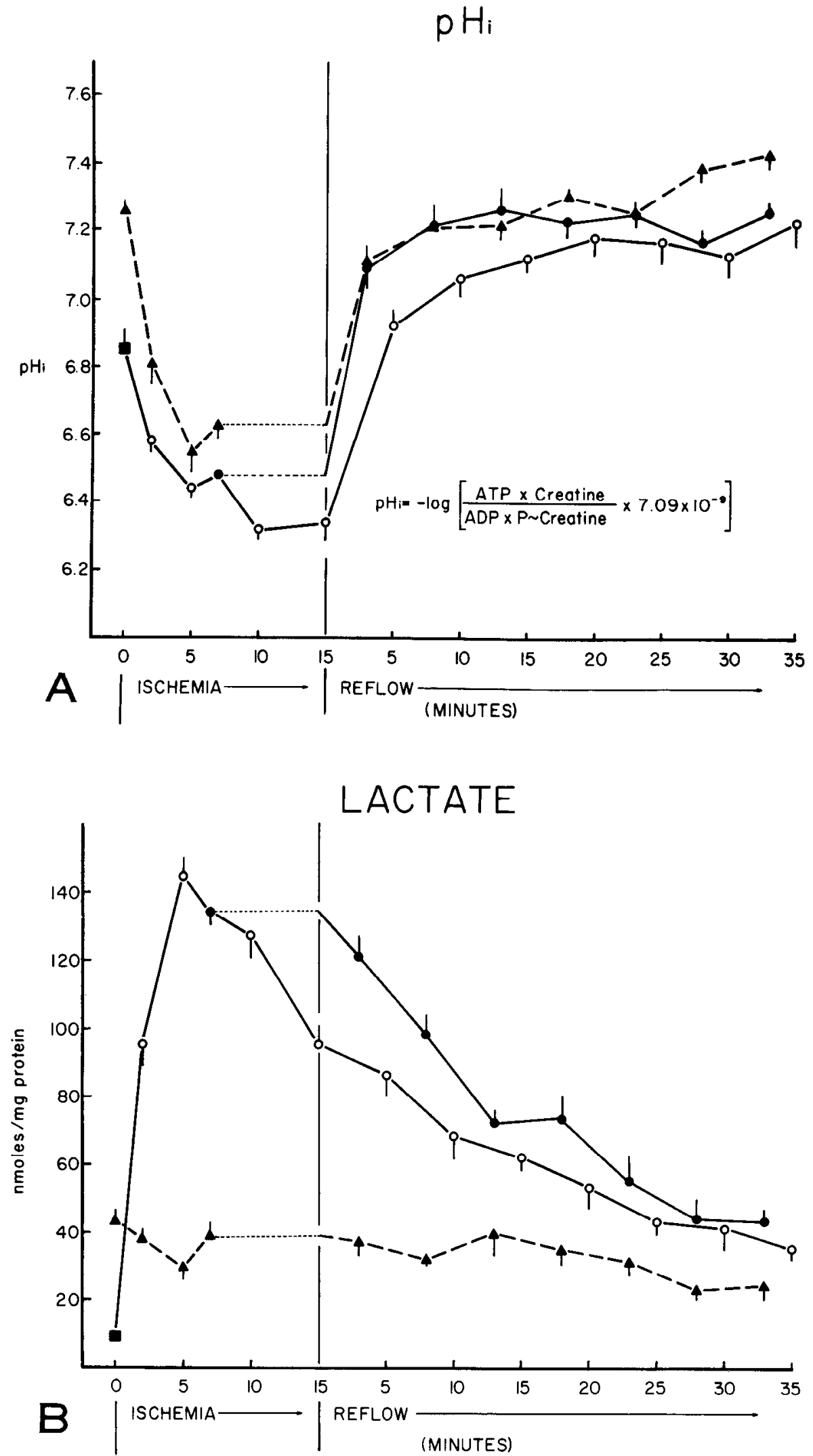

Figure 3. Changes in intracellular $\mathrm{pH}$ and lactate concentration from the same slices represented in Figure 1 (refer to Fig. 1 legend). Calculation of intracellular $\mathrm{pH}$ is discussed under "Materials and Methods." The in situ value of $\mathrm{pH}_{\mathrm{i}}$ was $6.85 \pm$ 0.06 , and the lactate concentration was $8.88 \pm 0.75 \mathrm{nmol} / \mathrm{mg}$ of protein. $A$, Intracellular $\mathrm{pH}\left(\mathrm{pH}_{\mathrm{i}}\right)$. $B$, Lactate concentration (in nanomoles per milligram of protein). $N=9$ to 13 for each experimental point; bars represent SEM. 

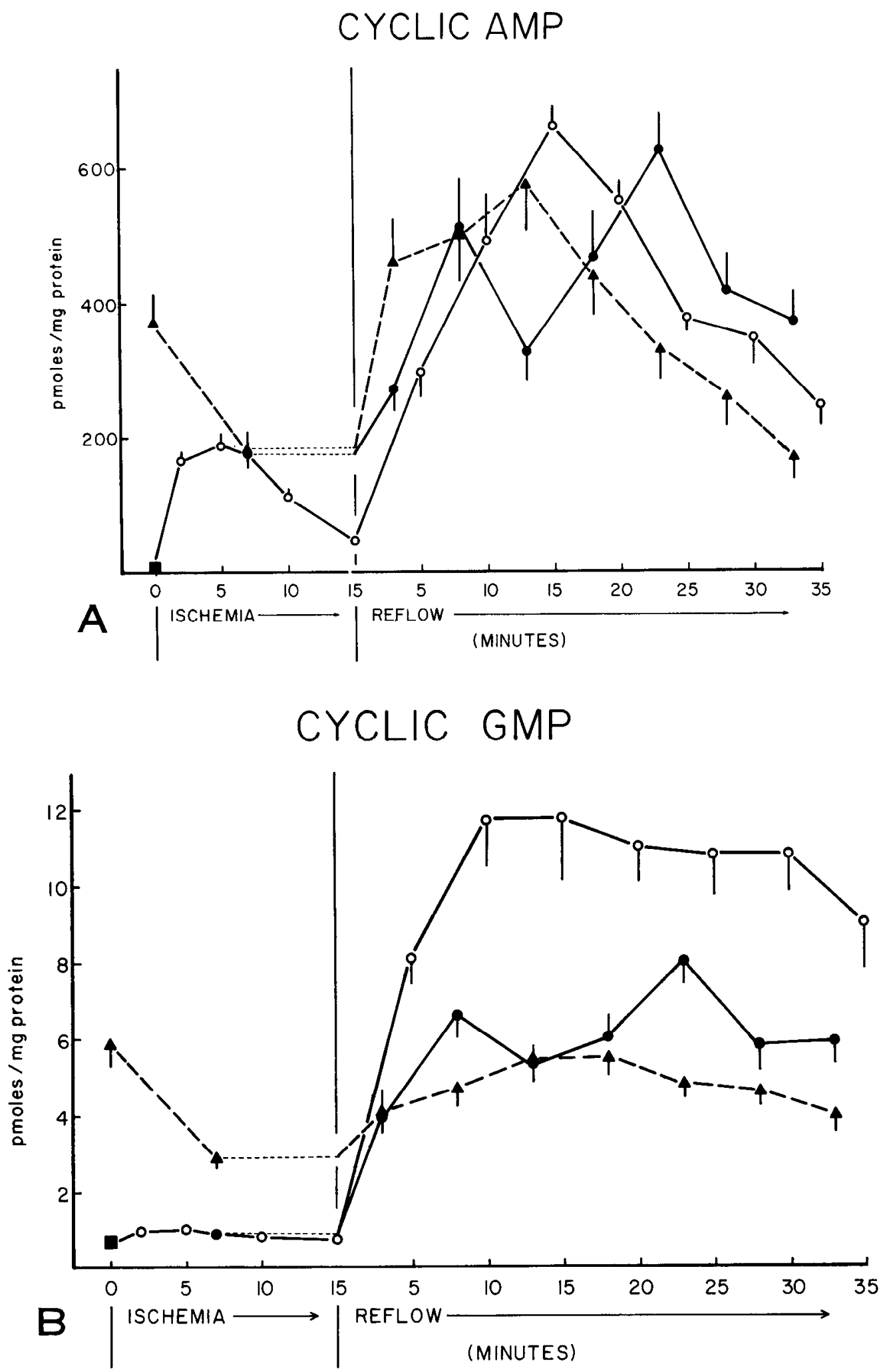

Figure 4. Changes in the cyclic nucleotide content of the slices represented in Figure 1 (refer to Fig. 1 legend). In situ levels of cAMP were $6.64 \pm 1.59 \mathrm{pmol} / \mathrm{mg}$ of protein, and those for cGMP were $0.64 \pm 0.06 \mathrm{pmol} / \mathrm{mg}$ of protein. $A$, Cyclic AMP. $B$, Cyclic GMP. $N=9$ to 13 for each experimental point; bars represent SEM.

\section{Discussion}

The present study indicates that the in vitro hippocampal slice preparation can be used to model some of the metabolic changes which occur during in vivo ischemia, in respect to both rate and magnitude of change. In this study decapitation produced an ordered sequence of metabolic shifts: a rapid fall in $\mathrm{PCr}$ concentration and rise 
in lactate and creatine levels was followed by more gradual decreases in ATP and energy charge. ADP and AMP levels rose as ATP content declined, with AMP peaking at a time when ADP concentration began to decline. These changes are in accordance with the postdecapitation observations of Lowry et al. (1964) and with a number of in vivo observations (Ljunggren et al., 1974; Kobayashi et al., 1977; Hansen and Nordstrom, 1979).

The in vitro model (secondary ischemia) produced a similar set of changes in several metabolites: PCr levels were minimal within 2 to $5 \mathrm{~min}$, as was seen following decapitation. Changes in energy charge, AMP, Cr, and $\mathrm{pH}_{\mathrm{i}}$ during the in vitro ischemia also resembled the changes which occurred following decapitation, although the magnitudes of the AMP and Cr peaks were decreased during the in vitro ischemia. The loss of the evoked response also occurred at a time similar to that required for in vivo ischemia and anoxia to abolish evoked potentials. For exmaple, $\mathrm{N}_{2}$ inhalation abolished evoked potentials within $3 \mathrm{~min}$ in area CA 1 of the in vivo hippocampus of cats and rabbits (Andersen, 1960), while ischemia had a similar effect within 1 to $2 \mathrm{~min}$ in mammalian cortex (Williams and Grossman, 1970; Branston et al., 1974) and spinal cord (Collewijn and Van Harrevald, 1966).

However, in vitro ischemia produced several metabolic changes which differ from those observed in vivo and following decapitation. ATP levels fell more rapidly in the in vitro model than following decapitation. This acceleration of the ATP deficit might readily be explained by the reduced levels of ATP and PCr at the onset of the in vitro ischemia. In addition, the decapitation ischemia would be expected to deplete glycogen (Lowry et al., 1964) which would further reduce the slices' ability to maintain ATP levels during the early period of in vitro ischemia.

ADP levels did not rise during in vitro ischemia, as opposed to the 9 -fold increase at $3 \mathrm{~min}$ of decapitation ischemia and the 3- to 4 -fold increase reported at 1 to 2 min of in vivo ischemia (Ljunggren et al., 1974; Kobayashi et al., 1977; Hansen and Nordstrom, 1979). The adenylate kinase equilibrium ([ATP][AMP]/[ADP $]^{2}$ ) calculated for in vivo brain tissue in control and ischemic conditions has been reported to be 0.72 and 2.64, respectively (Kobayashi et al., 1977). In the hippocampal slice, the calculated equilibrium was maintained near 1.75 during ischemia and recovery. When adenylate content is high, as for the in vivo situation, the equilibrium would be maintained when ATP falls only if ADP concentrations increased. In vitro slices have a much lower total adenylate content, allowing the equilibrium to be maintained when ATP falls with only an elevation in AMP.

Lactate levels did not rise during the in vitro ischemia, even though $\mathrm{pH}_{\mathrm{i}}$ exhibited a decrease similar to that following decapitation and in vivo ischemia (Ljunggren et al., 1974). The failure of lactate to increase during in vitro ischemia may result from the continued media flow during that period. This possibility is supported by the observation that lactate accumulates in postdecapitation slices maintained in a small volume of media but in the absence of flow. In addition, previous in vitro studies have shown that substantial lactate efflux occurs during electrical stimulation of neocortical tissue (Pull and McIlwain, 1972) and is thus available for washout.

Following decapitation, cAMP increased and cGMP remained constant, while both nucleotides increased during the recovery period. After $35 \mathrm{~min}$ of reflow, both cAMP and cGMP were elevated over control levels, and the concentrations of both decreased during the secondary ischemia. The in vitro conditions are markedly different from in vivo, including decreased total adenylates (and presumably guanine nucleotides) and abnormally high cyclic nucleotides at the onset of the second ischemic period.

During the recovery period there was a rise in $\mathrm{pH}_{\mathrm{i}}$ as well as the $\mathrm{PCr} / \mathrm{ATP}$ ratio. ATP, energy charge, lactate, and cyclic nucleotide levels responded more slowly to the return of glucose and oxygen. Although the initial rate of recovery was rapid, it appears that a longer recovery period is necessary to reach steady state levels in vitro than in vivo. Recovery rates were slower than those reported by Kobayashi et al. (1977) for gerbils exposed to $5 \mathrm{~min}$ of global ischemia. In that study, $\mathrm{PCr}$ levels stabilized in $5 \mathrm{~min}$, as did other energy-related compounds within $30 \mathrm{~min}$. The slow rate of recovery of energy compounds in brain slices has been noted previously (Rolleston and Newsholme, 1967) and is particularly pertinent to investigators using in vitro preparations, since slices may require recovery periods of greater than 30 min prior to data acquisition.

The $50 \%$ reduction in total adenylate and total creatine content of slices is a major consideration for metabolic studies on brain slices. The loss of these compounds occurred primarily during the postdecapitation ischemia and, in the case of the total adenylates, was greater than the $30 \%$ drop observed during 10 to $15 \mathrm{~min}$ of in vivo ischemia (Deuticke et al., 1966; Ljunggren et al., 1974). No similar loss occurred during the subsequent secondary, in vitro ischemia, and incubations up to $8 \mathrm{hr}$ showed no further decrease. The fall in metabolite concentration was relatively independent of the duration of ischemia and suggests that the adenylate and creatine deficits may be due to tissue trauma caused by slicing or the existence of isolated compartments within individual cells.

In these same slices, values expressed as a ratio (i.e., energy charge and $\mathrm{PCr} / \mathrm{ATP}$ ) more closely resemble in vivo values than do values expressed on a per milligram of protein basis. Thus, brain slices exhibit a marked loss of some metabolites but appear to maintain the remaining portion of those metabolites in approximately the same proportions as in vivo. These observations suggest that either there is a loss of tissue constituents throughout the slice, or that a portion of the tissue remains viable and retains metabolites in concentrations comparable to the in vivo tissue. The latter explanation appears to correlate well with the metabolic profiles and physiological responses obtained from recent studies in this laboratory (Lust et al., 1982).

The second goal in this study was to identify possible metabolic changes which result in recovery of the evoked response. The present data provide no indication that $\sim \mathrm{P}$ recovery corresponds to the return of evoked responses. There was a delay in the recovery of ATP and $\mathrm{PCr}$ and evoked responses in the 15-min ischemic group 
compared to the 7-min group. However, the concentration of $\sim \mathrm{P}$ was much lower in the 15 -min than in the 7 min ischemic group when the evoked potential returned. It does seem possible that the reduced magnitude of the maximal response may be related to the decreased energy stores in the slices which were ischemic for longer periods (Table I). A possible explanation for the lack of correlation between ATP concentrations and the maintenance of evoked potentials may be differences in local concentration. In an earlier study, Lipton and Whittingham (1982) found that the ATP concentrations in the molecular layer (synaptic region) correlated with transmission effects more closely than concentrations in the whole slice. The concentration of ATP in discrete layers of the hippocampal slice is being investigated.

The recovery of the evoked response also occurred while cyclic nucleotide levels were greatly elevated. This suggests that whole slice cAMP and cGMP levels are not indicative of the modulatory effect on transmission that has previously been demonstrated for some cortical neurons (Stone et al., 1975). However, the effects observed by Stone et al. were on spontaneous activity, and it is quite possible that the electrical stimulation used in this study was sufficient to overcome any effect which the cyclic nucleotides might exert on normal neuronal firing patterns.

The present results also indicate that there is a more rapid loss of $A T P, P C r$, and the evoked response in the absence of both glucose and oxygen than in anoxia alone (Lipton and Whittingham, 1982). This suggests the importance of anaerobic glycolysis and, therefore, ATP production in maintaining synaptic transmission during the early period of anoxia.

The preceding results indicate that the in vitro hippocampal slice preparation can be used to model several of the metabolic changes which occur during in situ ischemia, particularly those associated with the adenylates and PCr. A better understanding of steady-state brain slice integrity must exist before more detailed conclusions can be extended to the in vivo situation. The flexibility of the in vitro system might then allow more accurate temporal correlations to be made between metabolic perturbations and electrophysiological deficits.

\section{References}

Ames, A., III, R. L. Wright, M. Kowada, J. M. Thurston, and G. Majno (1968) Cerebral ischemia. II. The no-reflow phenomenon. Am. J. Pathol. 52: 437-453.

Andersen, P. (1960) Interhippocampal impulses. II. Apical dendritic activation of CA 1 neurons. Acta Physiol. Scand. 48: 178-208.

Atkinson, D. E. (1968) The energy charge of the adenylate pool as a regulatory parameter. Interaction with feedback modifiers. Biochemistry 7: 4030-4034.

Bosley, T. M., P. L. Woodhams, R. D. Gordon, and X. Balazs (1983) Effects of anoxia on the stimulated release of amino acid neurotransmitters in the cerebellum in vitro. J. Neurochem. 40: 189-201.

Branston, N. M., L. Symon, H. A. Crockard, and E. Pasztor (1974) Relationship between the cortical evoked potential and local cortical blood flow following acute middle cerebral artery occlusion in the baboon. Exp. Neurol. 45: 195-208.

Collewijn, H., and A. Van Harrevald (1966) Intracellular rec- ording from cat spinal motoneurones during acute asphyxia. J. Physiol. (Lond.) 185: 1-14.

Deuticke, B., E. Gerlach, and R. Dierkesmann (1966) Abbau freier nucleotide in herz, skeletmuskel, gehirn und leber der ratte bei sauerstoff mangel. Pflugers Arch. Ges. Physiol. 292: 239-254.

Hansen, A. J., and C. H. Nordstrom (1979) Brain extracellular potassium and energy metabolism during ischemia in juvenile rats after exposure to hypox'a for 24 h. J. Neurochem. 32: 915-920.

Harper, J. F., and G. Brooker (1975) Femtomole sensitive radioimmunoassay for cyclic AMP and cyclic GMP after $2^{\prime} 0$ acetylation by acetic anhydride in aqueous solution. J. Cyclic Nucleotide Res. 1: 207-213.

Hirsch, H., A. Bolte, A. Schaudig, and D. Tonnis (1957) Uber die wiederbelebung des gehirns bei hypothermie. Pflugers Arch. Ges. Physiol. 265: 328-336.

Kaasik, A., L. Nilsson, and B. K. Siesjo (1970) The effects of asphyxia upon the lactate, pyruvate and bicarbonate concentrations of brain tissue and cisternal CSF, and upon the tissue concentration of phosphocreatine and adenine nucleotides in anesthetized rats. Acta Physiol. Scand. 78: 448-458.

Kobayashi, M., W. D. Lust, and J. V. Passonneau (1977) Concentrations of energy metabolites and cyclic nucleotides during and after bilateral ischemia in the gerbil cerebral cortex. J. Neurochem. 29: 53-59.

Lipton, P., and T.S. Whittingham (1979) The effect of hypoxia on evoked responses in the in vitro hippocampus. J. Physiol. (Lond.) 287: 427-438.

Lipton, P., and T. S. Whittingham (1982) Reduced ATP concentration as a basis for synaptic transmission failure during hypoxia in the in vitro guinea pig hippocampus. J. Physiol. (Lond.) 325: 51-65.

Lipton, P., and T. S. Whittingham (1983) Energy metabolism and brain slice function. In Brain Slices, R. Dingledine, ed., Plenum Press, New York, in press.

Ljunggren, B., H. Schultz, and B. K. Siesjo (1974) Changes in energy state and acid-base parameters of the rat brain during complete compression ischemia. Brain Res. 73: 277-289.

Lowry, O. H., and J. V. Passonneau (1972) A Flexible System of Enzymatic Analysis, Academic Press, Inc., New York.

Lowry, O. H., N. J. Rosebrough, A. L. Farr, and R. J. Randall (1951) Protein measurement with the Folin phenol reagent. J. Biol. Chem. 193: 265-275.

Lowry, O. H., J. V. Passonneau, F. X. Hasselberger, and D. W. Schulz (1964) Effect of ischemia on known substrates and cofactors of the glycolytic pathway in brain. J. Biol. Chem. 239: 18-30.

Lust, W. D., G. K. Feussner, E. K. Barbehenn, and J. V. Passonneau (1981) The enzymatic measurement of adenine nucleotides and P-creatine in picomole amounts. Anal. Biochem. 110: 258-266.

Lust, W. D., T. S. Whittingham, and J. V. Passonneau (1982) Effects of slice thickness and method of preparation on energy metabolism in the in vitro hippocampus. Soc. Neurosci. Abstr. 8: 1000.

MacMillan, V., and B. K. Siesjo (1972) Intracellular $\mathrm{pH}$ of the brain in arterial hypoxemia evaluated with the $\mathrm{CO}_{2}$ method and from creatine phosphokinase equilibrium. Scand. J. Clin. Lab. Invest. 30: 117-125.

Pull, I., and H. McIlwain (1972) Metabolism of $\left({ }^{14} \mathrm{C}\right)$ adenine and derivatives by cerebral tissues, superfused and electrically stimulated. Biochem. J. 126: 965-973.

Rolleston, F. S., and E. A. Newsholme (1967) Control of glycolysis in cerebral cortex slices. Biochem. J. 104: 524-533.

Rose, I. A. (1968) The state of magnesium in cells as estimated from the adenylate kinase equilibrium. Proc. Natl. Acad. Sci. U. S. A. 61: 1079-1086. 
Steiner, A. L., C. W. Parker, and D. M. Kipnis (1972) Radioimmunoassay for cyclic nucleotides. I. Preparation of antibodies and iodinated cyclic nucleotides. J. Biol. Chem. 247: 11061113.

Stone, T. W., D. A. Taylor, and F. E. Bloom (1975). Cyclic AMP and cyclic GMP may mediate opposite neuronal responses in the rat cerebral cortex. Science 187: 845-847.

Urbanics, R., E. Leninger-Follert, and D. W. Lubbers (1979) Extracellular $\mathrm{K}^{+}$and $\mathrm{H}^{+}$activities in the brain cortex during and after a short period of ischemia and arterial hypoxia. Adv. Exp. Med. Biol. 94: 611-616.
Waddell, W. J., and T. C. Butler (1959) Calculation of intracellular $\mathrm{pH}$ from the distribution of 5,5-dimethyl-2,4-oxazolidinedione (DMO) Application to skeletal muscle of the dog. J. Clin. Invest. 38: 720-729.

Whittingham, T. S., and P. Lipton (1981) Cerebral synaptic transmission during anoxia is protected by creatine. J. Neurochem. 37: 1618-1621.

Williams, V., and R. G. Grossman (1970) Ultrastructure of cortical synapses after failure of presynaptic activity in ischemia. Anat. Rec. 166: 131-142. 